\title{
Properties of Alumina-Magnesia Cutting Tools
}

\author{
Hayder K. Rashid Mohammed A. S. Khudher \\ University of Babylon, College of Materials Engineering
}

\begin{abstract}
The high speed cutting tools that made from ceramic materials, alumina based, it is very important for the machining process. It has a hot hardness and abrasive resistance and chemical stability at the high temperature, but it has a brittleness and low fracture strength. In this study, synthesis samples from the $\alpha$-alumina $\left(\mathrm{Al}_{2} \mathrm{O}_{3}\right)$ doping with magnesia $(\mathrm{MgO})$ with different percentage $(0.35,0.75,1.1 \%$ wt.) and compare with the pure alumina properties. It is using cold uniaxial pressing $(200 \mathrm{MPa})$ and sintered at $\left(1500^{\circ} \mathrm{C}\right)$ remain three hours for this samples. The purpose was to study the effect of the doping on the mechanical and physical properties and the ability to enhancing it. Numerical simulation was worked for the contact and friction between the ceramic cutting tool and the workpiece material (AISI 1006 steel). This numerical methods dependent on ABAQUS Ver.6.14 program. The results show that ability of cutting and chip formation and successfully propagation through this type of cutting tools without failure it at high speed $(150-250) \mathrm{m} / \mathrm{min}$. Also, the stress and heat generated due to ceramic cutting tool was presented The result appeared increasing in the hardness and the density value by the doping with $\mathrm{MgO}$. By increase the percentage of magnesia that given enhanced the properties. The $\mathrm{MgO}$ as a second phase reduce alumina grain size and increase the hardness and the wear resistance to cutting tools. Small amount of magnesia enhanced the densification rate grain growth and accelerate the sintering rate. The magnesia doping enable to sinter the mixture alumina-magnesia to near theoretical density. The best result was found with $0.75 \% \mathrm{MgO}$ at $1500^{\circ} \mathrm{C}(\mathrm{HV} 19 \mathrm{GPa})$.
\end{abstract}

Keywords: ceramic, cutting tool, Johnson cook, Abaqus ,numerical.

DOI: $10.7176 /$ IEL/9-3-05

Publication date: April $30^{\text {th }} 2019$

\section{Introduction}

Ceramics are the high class of tool materials with potential for a wide range of high speed finishing operations as well as for high removal rate machining of difficult to machine materials. In metal cutting process, it is very important the increasing metal removal rate for higher productivity demands cutting tools. As well, with high wear resistant properties and higher reliability under adverse cutting conditions.

Alumina cutting tools with doping by magnesia lead to inhabit the grain growth and increasing the density and hardness and obtain long life tools and good performance in machining process. The general performance of cutting tool is depended on; geometry of cutting tool, environments and the machining conditions, material of cutting tool, use of those tools and proper selection and the most vital role plays is the tool material.

In this study, two items will be addressed. First, the most common erosion criterion, a critical failure strain, will be discussed with a view to finding a rational approach to selecting an appropriate failure strain. This is the criterion used for most of the subsequent simulations in this document. The law chosen to represent the physique of the process is that of Johnson-Cook, usually used in the literature to simulate this type of operation. Edgar Santos et al (2008) were presented studying the friction behavior of (alumina-magnesia) toward steel type_Ck45K and compare with zirconia against same steel type. Coefficient of friction and dissipated energy in the contact is considered in the comparative studying. Alumina ceramics present more friction coefficient and contact temperature than zirconia ceramics. While, Asnaf Aziz (2012) studied the heat flex that induced from the friction. Also, MR. B. V. R. M. Kumar et al (2016) they developed the finite element model depending on ABAQUS/Explicit that used to simulate and analysis the effects of temperature at turning. A WC tool coated with TiN is considered as tool and AISI 4340 Steel is considered to be the workpiece and analysis were conducted to investigate the temperature profile. However, S. Sulaiman and et al (2014) they used FEM to simulated the damage that occur on cutting tools depend on ABAQUS program. As well as, A Keyan Wang and B. Eng.(2016) studied the finite element analysis (FEA) of a numerical method widely used to predict the metal-cutting performance in both academic and industrial studies, avoiding the high expense and time consumption of experimental methods. The problem is how to calibrate reliable fracture-parameters as chipseparation criterion are implemented into FEA modeling.

The aims of this study considers the following points:

1) Synthesis samples of the magnesia- alumina cutting tools and study the physical and mechanical properties.

2) Study the characterizes of alumina doping magnesia cutting tools and know the effect of increasing the percentages of magnesia.

3) Improving the density and hardness of alumina cutting tools.

4)Investigate the effect of cutting speed and uncut chip thickness on cutting performance and apply the Finite 
Element Method (FEM) based on the ABAQUS software which involves Johnson-Cook material mode and Coulomb's friction law.

\section{Cutting Materials Characteristics}

The materials of cutting tool should have a many important characteristics to avert severe wear, high temperature in the cut process, and fracture failure. Because the high frictions forces between the cutting tool and the surface material and high temperature generator, losing in the contact surfaces happen. Another important characteristics include surface finish on the tool ,chemical inertness of the tool material with respect to the work material, and thermal conductivity of the tool material, which affects the maximum value of cutting temperature at tool-chip interface shown as in Figure (1)[4].
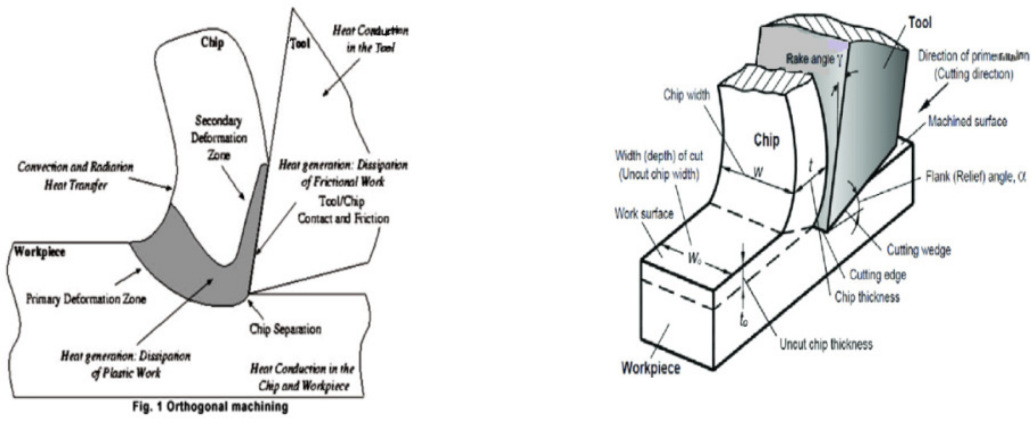

Figure (1): The cutting tool-chip contact surfaces and deformation zone.

There are many type geometry of ceramic cuting tools of alumin with white or pink colour depending on the addiding of mateials to the alumina the Figure (2) showing some types of cutting tools.
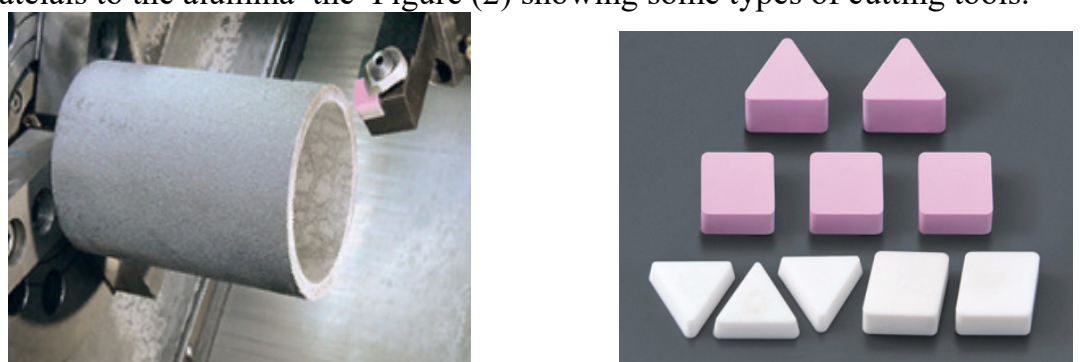

Figure (2): Some types of ceramic cutting tool for machining process.

Another characters for ceramic materials is Toughness, Hardness, At high temperature, also named hot hardness, so that the tool edge hardness and strength are maintained in high temperatures of cutting. The material ability to absorb the energy without failing occur. The cutting process if it is interrupted and greatly accompanied by impact forces especially, and cutting tool if it isn't strong sufficient, this lead to the cutting tool is may be failing early.

\section{Magnesia}

Magnesium oxide or Magnesia, it is a white hygroscopic solid mineral that occurs naturally as Pericles and is a source of magnesium. It has chemical formula of $(\mathrm{MgO})$ its consists of a lattice from $\mathrm{Mg}^{2}$ ions and $\mathrm{O}^{2-}$ ions held together by ionic bonding. Magnesia structure is as shown in Figure(3). In the presence of water magnesium hydroxide forms as in equation (1)[6]:

$$
\mathrm{MgO}+\mathrm{H} 2 \mathrm{O} \rightarrow \mathrm{Mg}(\mathrm{OH})
$$

Also can be can be reversed by heating it to separate moisture. Magnesia is produced by the calcination of magnesium hydroxide or magnesium carbonate.This is obtained by the treatment of magnesium chloride solutions, typically seawater, with the lime as in equation (2) [6]

$$
\mathrm{Mg}^{2}+\mathrm{Ca}(\mathrm{OH})_{2} \rightarrow \mathrm{Ca}^{2}+\mathrm{Mg}(\mathrm{OH})_{2}
$$

Produces magnesium oxide of different reactivity by claiming at different temperatures. 


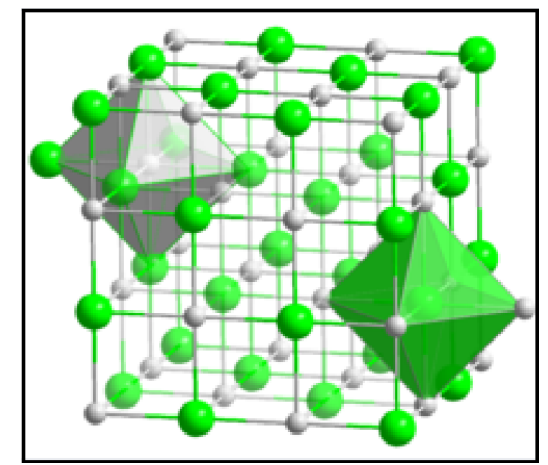

Figure (3): Magnesia structure( $\mathrm{Mg}^{2}$ ions and $\mathrm{O}^{2-}$ ions held together by ionic bonding).

\section{Experimental}

This chapter was classified into three stages: preparation of the raw materials stage, preparation of the specimens stage and completion of the examination stage. The Figure (4) shows the schematic diagram which illustrates all experimental stages

illustrates all experimental stages.

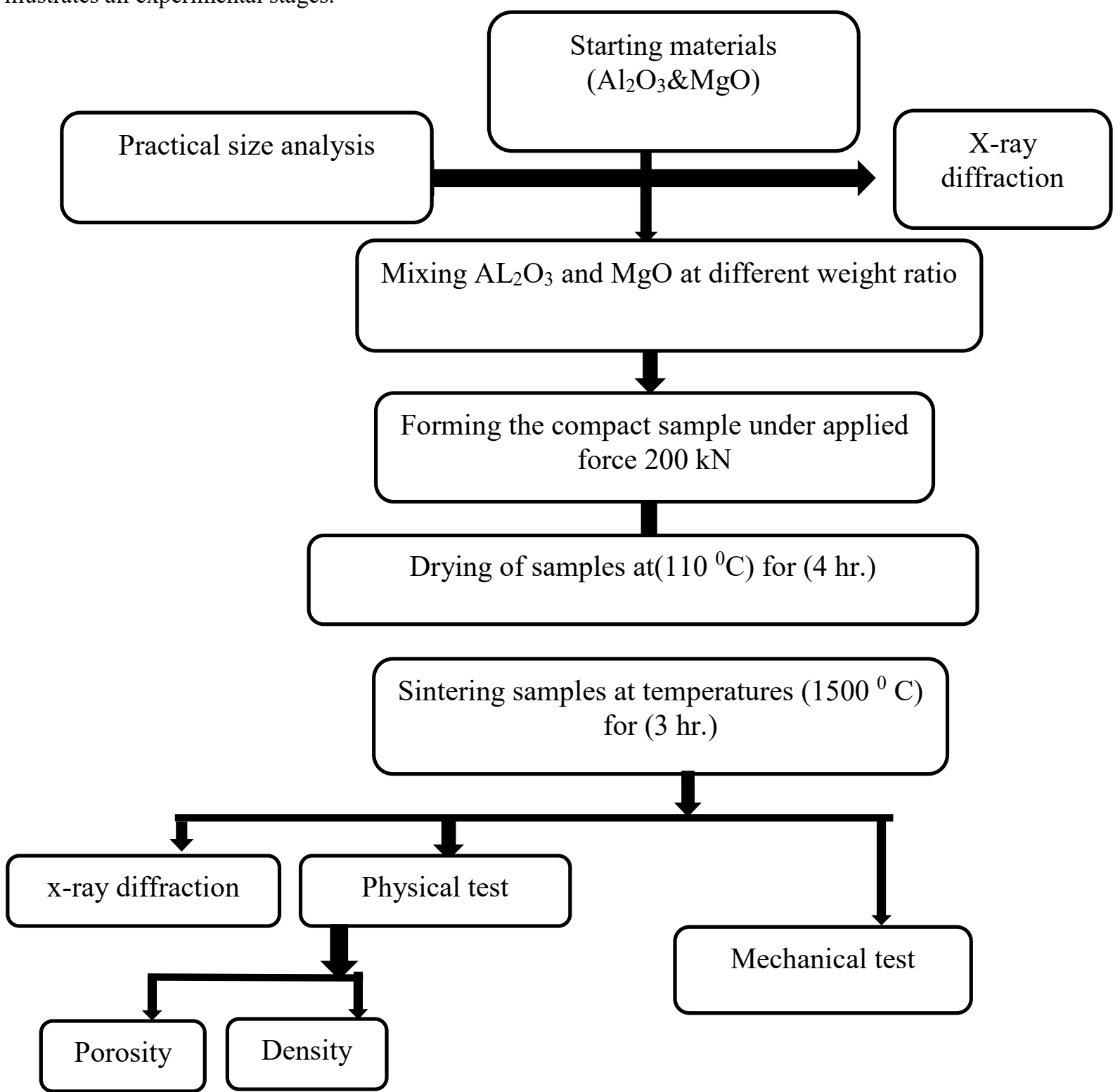

Figure (4): Steps to prepare $\left(\mathrm{MgO}-\mathrm{Al}_{2} \mathrm{O}_{3}\right)$ cutting tools. 
The sintered was done according to the thermal cycle outlined as follows in Figure (5). It is raising from room temperature in $\left(15{ }^{\circ} \mathrm{C} / \mathrm{min}\right)$ up to $1500{ }^{\circ} \mathrm{C}$, where it stayed for 3 hours and then after this it lower in rate $(15$ $\left.{ }^{\circ} \mathrm{C} / \mathrm{min}\right)$.

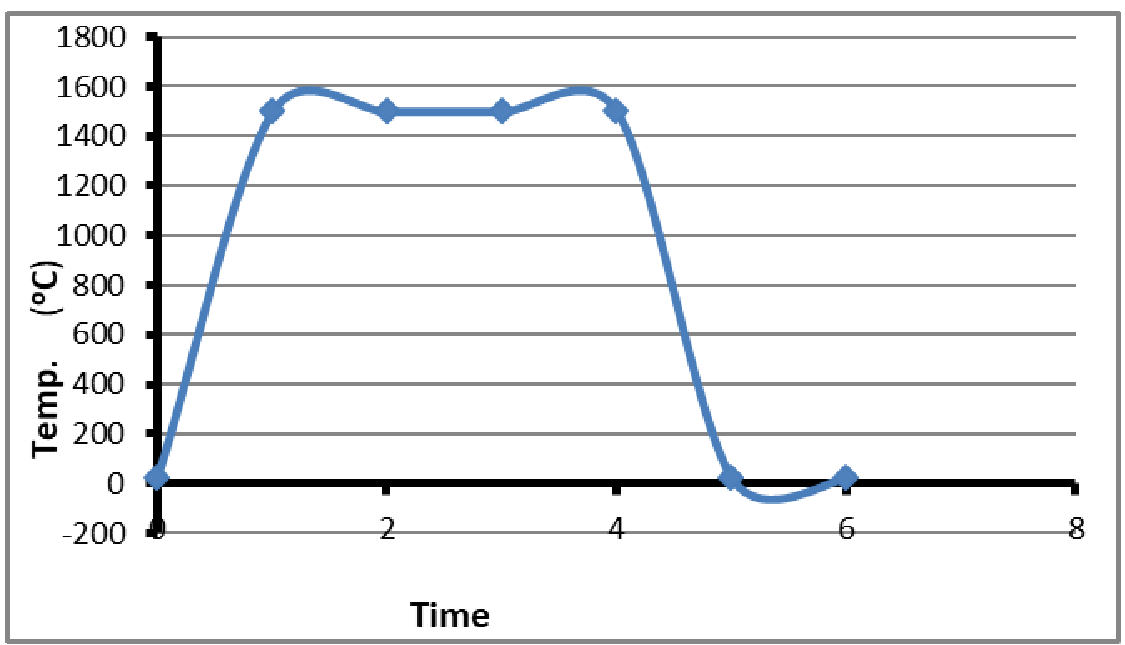

Figure (5): The thermal cycle for the sintering of specimens.

It was utilized the furnace at the University of Babylon-college of Materials Engineering show in Figure (6). The samples were immersed in graphite powder to prevent the oxidation

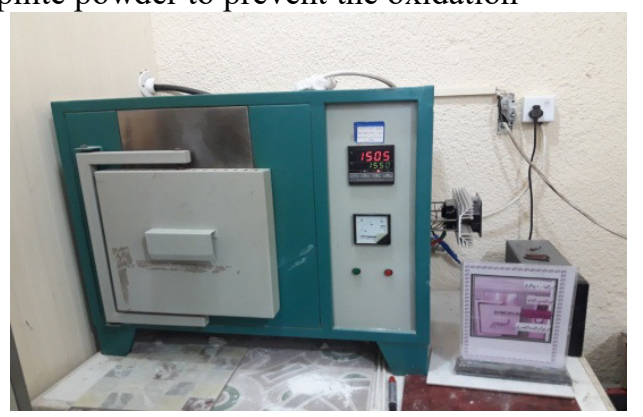

Figure (6): The sintering furnace.

The specimens were tested according to ASTM (373-88) by Archimedes method with a cylinder shape for each batch. Test specimens were oven dried at $110^{\circ} \mathrm{C}$ for 24 hours. The cooling process was done in a desiccator and their dry weight (D). These were placed in a glass beaker contained wastilled water and boiled for 5 hours, then soaked for an additional 24 hours. The suspended weight (S) and saturated weight (M) were recorded using digital dwasplay (DSJ-5) as shown in Figure (7). The apparent porosity was calculated using equation (3); $\mathrm{P}=[(\mathrm{M}-\mathrm{D}) / \mathrm{V}] \times 100$

Where; $\mathrm{P}=$ porosity $\%, \mathrm{M}=$ saturated weight $(\mathrm{g}), \mathrm{D}=$ dry weight $(\mathrm{g}), \mathrm{V}=$ the exterior volume which calculated by; (V=M-S), where; $\mathrm{S}=$ suspended weight $(\mathrm{g})$.

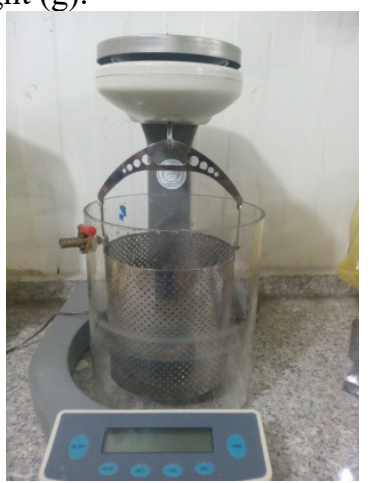

Figure (7): Digital dwasplay hydrostatic dynamic balance

Many Mechanical Properties was calculated as will show in subsequent articles. The Three Points Bending test is according to the same conditions, by using the rectangular bar specimens with the dimensions of $(60 \times 5 \times 4) \mathrm{mm}$. This test was done according to ASTM C1161 by using universal testing machine . 


\section{Numerical Analysis}

Finite element analysis (FEA) can be used to solve complex structural problems in the various engineering fields. ABAQUS is used in this work to simulate chip formation. The ABAQUS released in 1978 and developed by Dr. Habbitt, Dr. Karlson and Dr. Sorensen which depends on finite element method. The damage of materials in life is very expensive. Consequentially, their analysis is one of most important applications for simulation depends on FEA. The Johnson Cook method is used in ABAQUS to simulate the damage and chip-formation using ceramic cutting tools. All properties of damage parameter were calculated experimentally for cutting tool and specimen.

Table (1) that contain the properties of AISI 1006 steel [7], Table (2) which contain the properties of ceramic cutting tool [8], and Table (3) which contain the cutting parameter selected for numerical test[9].The damage analysis depends on Johnson-cook method .

Table (1): Mechanical and thermal properties of AISI 1006 Steel [7].

\begin{tabular}{|c|c|c|c|}
\hline Density ( $\rho)$ & $7850 \mathrm{~kg} / \mathrm{m}^{3}$ & Yield stress $\left(\sigma_{\mathrm{y}}\right)$ & 350 MPa \\
\hline Young modulus (E) & $220 \mathrm{GPa}$ & Room temperature (T) & $25^{\circ} \mathrm{C}$ \\
\hline Poisson's ratio (v) & 0.30 & Specific heat capacity (cp) & $4500 \mathrm{~J} / \mathrm{kg}^{\circ} \mathrm{C}$ \\
\hline Shear modulus (G) & $82 \mathrm{GPa}$ & & \\
\hline
\end{tabular}

Table (2): Mechanical properties for ceramic cutting tool [8].

\begin{tabular}{|l|c|}
\hline Type & Alumina magnesia \\
\hline Composition & Al2O3+ 0.75\% MgO \\
\hline Density $\left(\mathrm{g} / \mathrm{cm}^{3}\right)$ & 3.97 \\
\hline Compressive strength $\left(\mathrm{kN} / \mathrm{mm}^{2}\right)$ & 4.0 \\
\hline Yong Modules $\left(\mathrm{kN} / \mathrm{mm}^{2}\right)$ & 380 \\
\hline Poisson Ratio & 0.24 \\
\hline
\end{tabular}

Table (3): Cutting parameter selected for numerical test [9].

\begin{tabular}{|l|c|}
\hline Cutting speed $\left(\mathrm{V}_{\mathrm{c}}\right)$ & $150 \mathrm{~m} / \mathrm{min}$ \\
\hline Feed rate $(\mathrm{W})$ & $0.17 \mathrm{~mm} / \mathrm{rev}$ \\
\hline Depth of cut $\left(\mathrm{t}_{1}\right)$ & $0.5 \mathrm{~mm}$ \\
\hline Rake angle & $-6^{\circ}$ \\
\hline
\end{tabular}

The tool-chip contact length presented is calculated by equation (1) and equation (2) as follow[10];

\section{Meshing}

The parts that exposed to contact and deformation by the force applied was simulated in the program by small elements to all the bodes studying. The tool modeled using nodes and element, for achieve accurate result the machining simulation, the mesh division of the workpiece preformed into nodes and elements at tool and workpiece were partitioned with finer mesh near the contact zone.

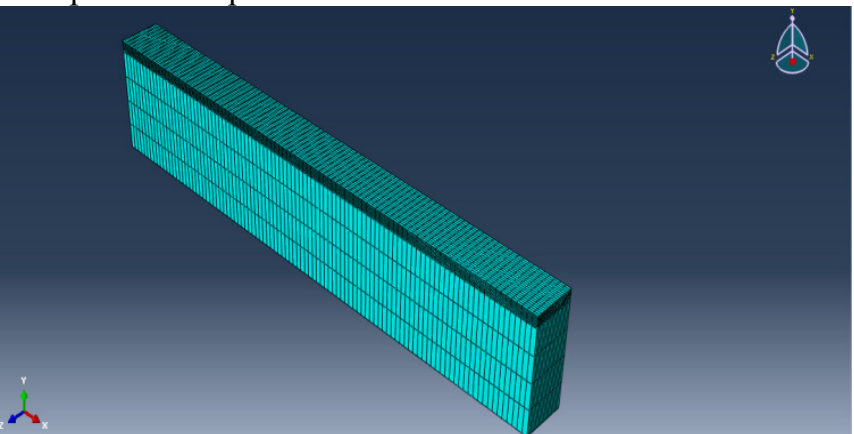

A

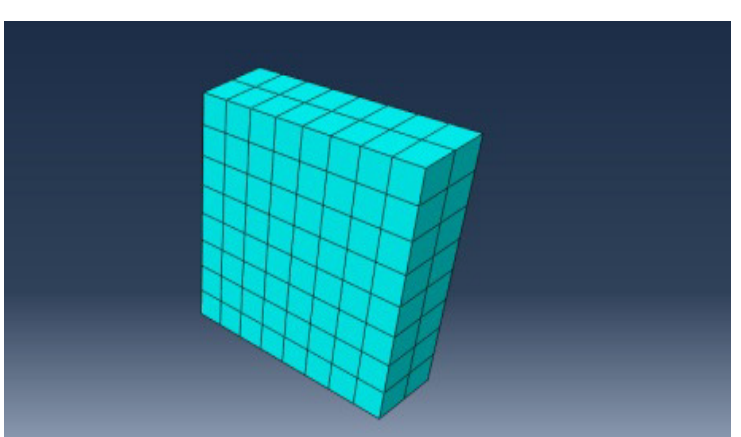

B

Figure (8): The parts are completed definitions and meshing; (A)workpiece (B) cutting tool.

In this study the sides that were examined include the effect of the change of some parameter of the module to reach to the optimal chosen of the geometry, by choose the rake angle $6^{\circ}$ compare with $8^{\circ}$ for the position of cutting tool and the better machining that can result. Anther parameter was choose the average speed of cutting $200 \mathrm{~m} / \mathrm{min}$, to known the stresses occur and its distributions, also the heat generation from friction between the cutting tool and workpiece that result from the cutting process and its distribution.

\section{Experimental results}

The experimental results related with ceramic cutting tool that prepared. The sintered samples are scanned in 
diffraction angle $(2 \theta)$ from $20^{\circ}$ to $70^{\circ}$ as shown in Figure (9). This result was matched with card No.(00-00-100). From Figure we can observed the compound $\left(\mathrm{AlO}_{2} \mathrm{Mg}\right)$, And ( $\left.\mathrm{Al} 2 \mathrm{O} 3\right)$.

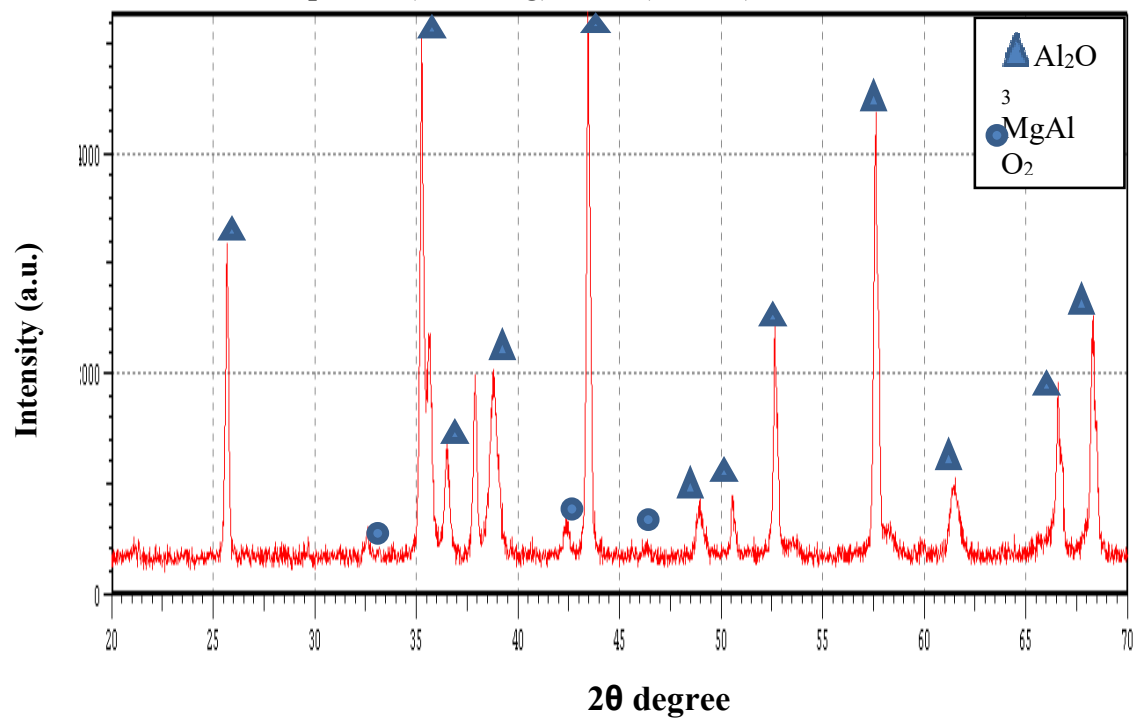

Figure (10): XRD analysis of compact sample $(0.75 \% \mathrm{MgO})$.

The Figure (11) and figure (12) were explained the results from micro-hardness at load of $(9.81 \mathrm{~N})$ and holding time $(15 \mathrm{sec})$ of the pure alumina and alumina doped magnesia with different weight ratio ( $0.35,0.75$ and $1.1 \mathrm{wt} . \%)$. In general during the Vickers test, there are many loads were used, like $(100,200,300,400,500 \mathrm{~g})$ could not give any track on the sample surface.

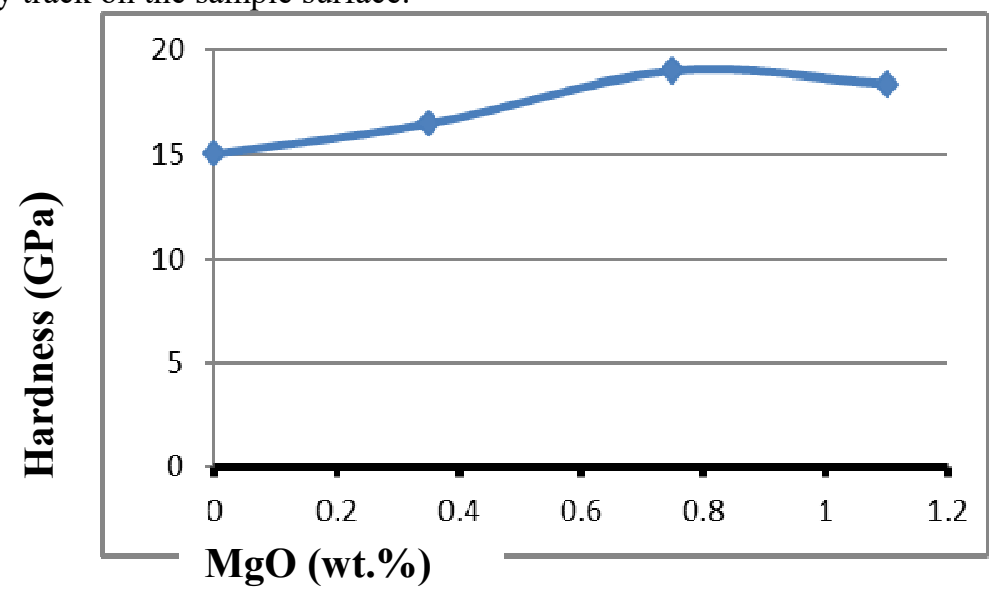

Figure (11): The relation between Vickers Hardness and $\mathrm{MgO} \%$ added.

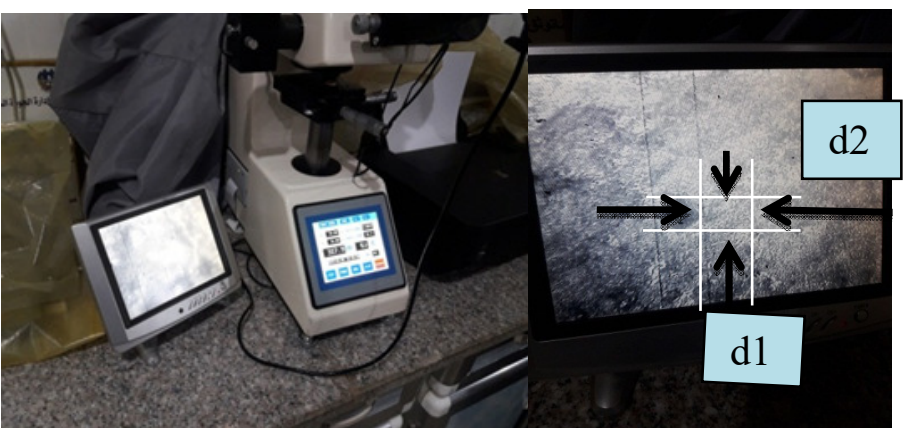

Figure (12): Optical microscope of Vickers trace, for alumina $+0.75 \% \mathrm{MgO}$.

It can be observed that the hardness of pure sample and doped samples in the range (15-18) GPa. The pure sample of $\mathrm{Al}_{2} \mathrm{O}_{3}$ was highest Hardness about $(15.10 \mathrm{GPa})$ but with increase the weight ratio $\mathrm{MgO}$ in $\mathrm{Al}_{2} \mathrm{O}_{3}$ caused increase the hardness due to inhabit the grain growth of alumina and increasing the density. The increased of the additive of the magnesia to the alumina matrix was increased the bending strength, where it is 
variation from $\left(28 \mathrm{~kg} / \mathrm{mm}^{2}\right)$ to $\left(35 \mathrm{~kg} / \mathrm{mm}^{2}\right)$ depending on the ratio of magnesia. The figure (13) shows the variation in the bending strength depending on the magnesia addition.

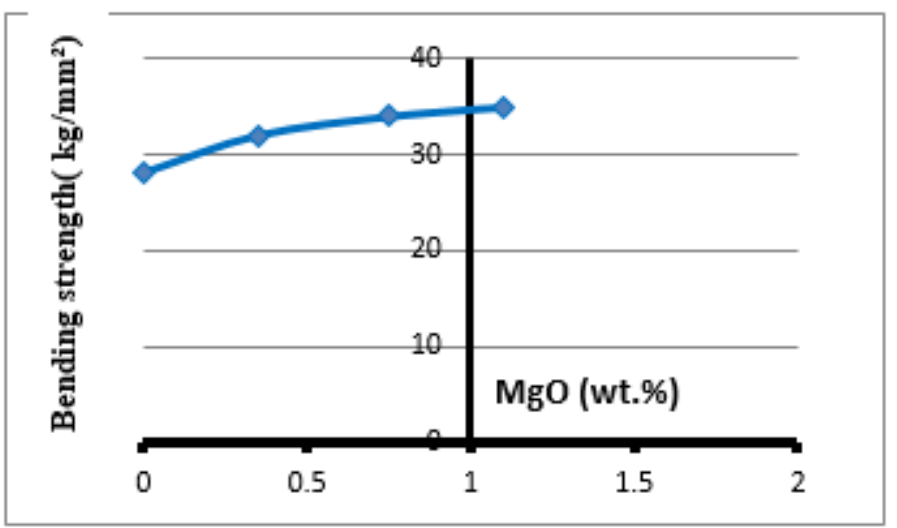

Figure(13): The relation between bending strength and magnesia content 3 point flexural strength test.

Thermal conductivities were compared for different content of $(\mathrm{MgO})$ with alumina matrix at the same temperature $\left(1500^{\circ} \mathrm{C}\right)$. Figure (14) was shown the relationship between the thermal conductivity and different weight percent of magnesia.

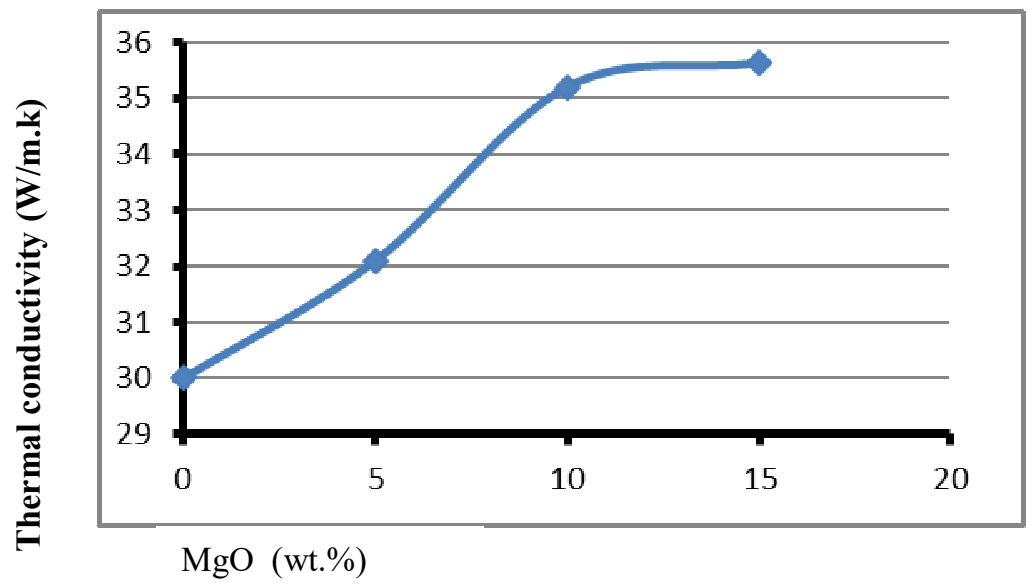

Figure (14): Thermal conductivity with magnesia content in alumina matrix.

\section{Numerical results}

The prediction of cutting tool stresses by finite element analysis and so the type of tool wear can be determined in hard tuning processes. The cutting at began start deformation the workpiece at high speed $200 \mathrm{~m} / \mathrm{min}$ and cutting it without stains or failure in the tools, as show in Figure (15 A) and Figure (15 B) the cutting was be successful and the workpiece machining and the tool withstand without failure. 


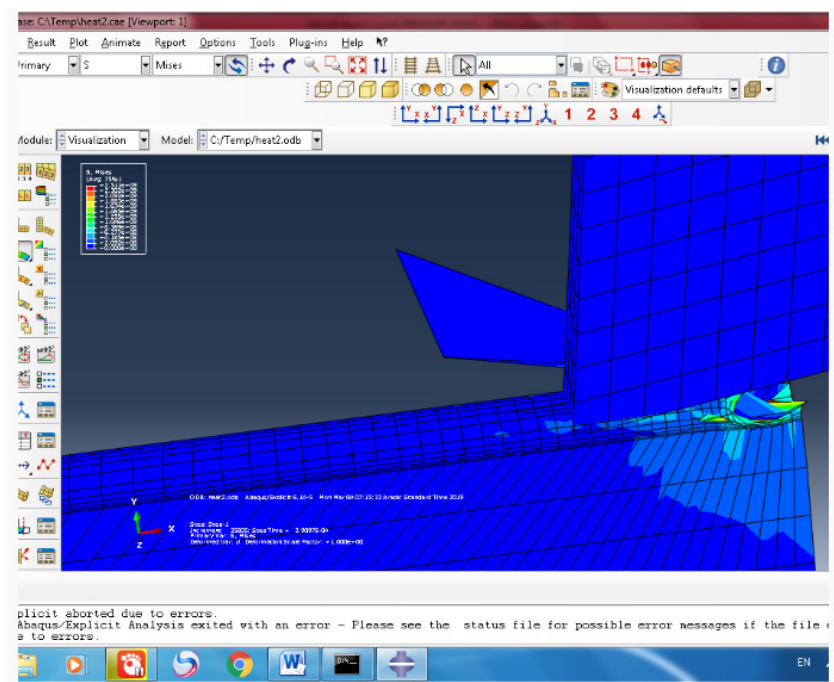

A

Figure (15): A)The results of Von Messes stresses distribution in the cutting module, rake angle $6^{\circ}$ with $200 \mathrm{~m} / \mathrm{min}$. B) Von Messes Stresses on the workpiece distribution at rake angle $8^{\circ}$

The Figure (16) shows the heat distribution at the rake angle $6^{\circ}$. The effect zone by the temperature was in the front and in the middle of the contact area between the cutting tool and workpiece. The change in feed shown in figures $(15 \mathrm{~A})$ and $(16)$ with the same rake angle $6^{\circ}$. As shown in these figure the high speed will produce damage grater that compare with the less feed and the stress will increase.

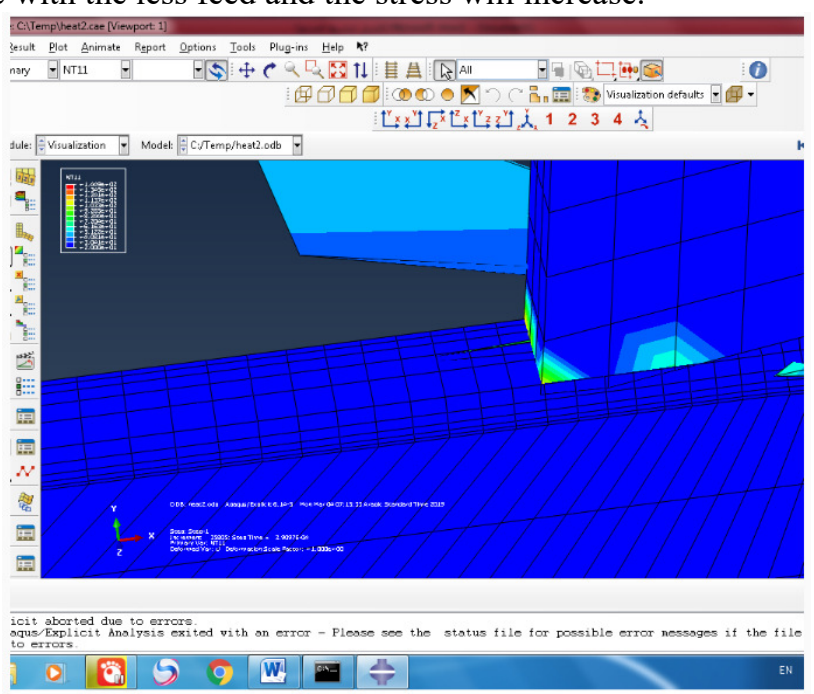

Figure (16): The result of heat distributed in the module at rake angle $6^{\circ}$ with $200 \mathrm{~m} / \mathrm{min}$ speed.

This mean to get a uniform chip formation can be obtained with low feed. In figure (18) the rake angle increased to $8^{\circ}$ with the same feed $200 \mathrm{~m} / \mathrm{min}$ as shown in figure $(15 \mathrm{~A})$. This figure presented that the increase in rake angle will make the stress and energy for damage will decrease. Moreover, the chip formation is more easer. 


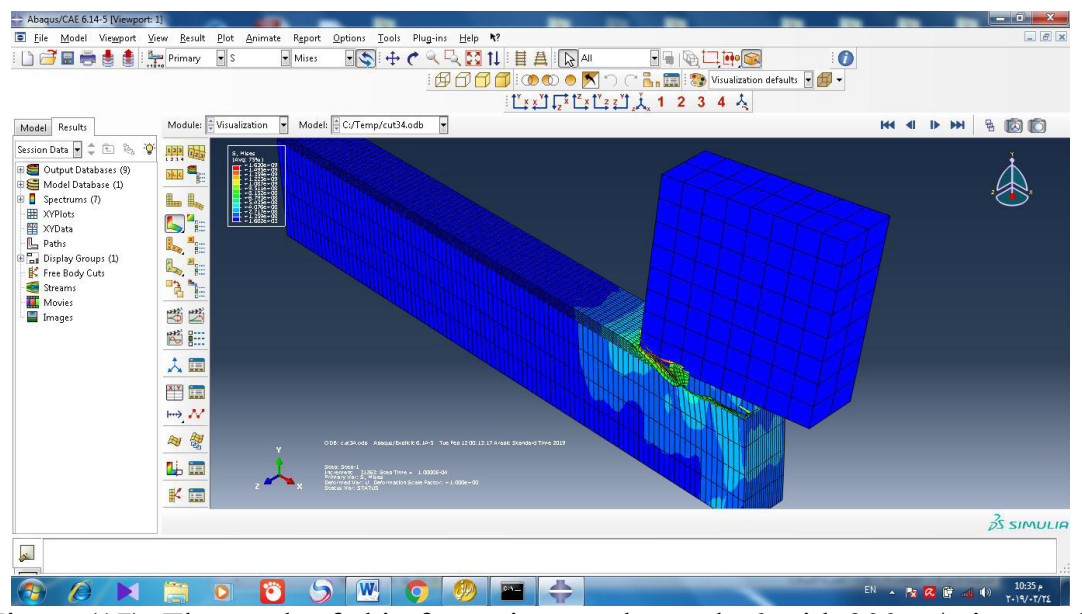

Figure (17): The result of chip formation at rake angle $6^{\circ}$ with $300 \mathrm{~m} / \mathrm{min}$ speed.

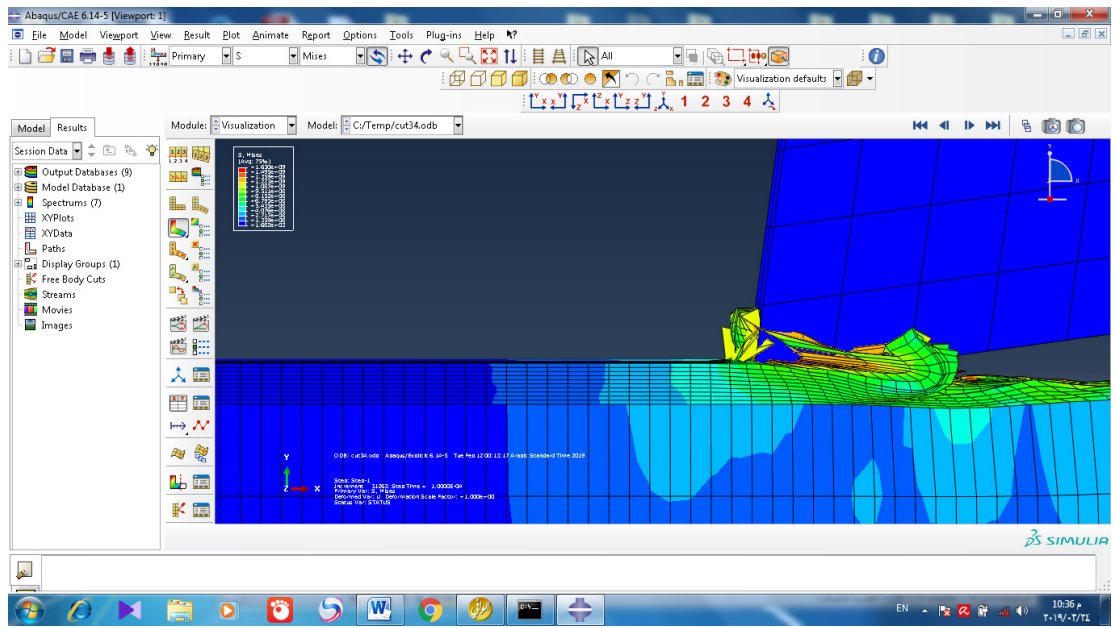

Figure (18): The result of chip formation at rake angle $8^{\circ}$ with $200 \mathrm{~m} / \mathrm{min}$ speed.

\section{Conclusions}

The conclusion of this study can be summers in the following points:

1 -The alumina-magnesia cutting tool was successfully synthesized by pressing and sintering at $\left(1500{ }^{\circ} \mathrm{C}\right)$ for 3 hour.

2-Vickers Hardness of alumina ceramic is increased with increased magnesia content.

3-ABQUS results of this situation revealed that the model of tool-chip contact area and boundary conditions for applying cutting force components on this area is correct.

4- The cutting and friction forces was distributed near to the chip form and decrease gradually far from it.

\section{References}

1.F. Paulo Davian and Edgur Santos(2008), department of mechanical Engineering, University of Aveiro, Aveiro, Portugal; and Catarina Pereira and F.M.F. Ferreira; Department of ceramics and Glass Engineering, CICECO University of Aveiro, Aveiro, Portugal.

2. Asnaf Aziz, (2012)."SIMULATION OF THERMAL STRESSES IN A DISC BRAKE" Thesis, School of Engineering in Jonkoping.

3. Mr. B V. R. M. Kumar, Dr. K. Hemachandra Reddy and Dr. Ch. R. Vikram Kumar (2016). " Finite Element Model Based On ABAQUS / Explicit To Analyze The Temperature Effects Of Turning "International Journal of Applied Engineering Research ISSN 0973-4562 Volume 1, Number 8 pp 5728-5734.

4.S. Sulaiman, Soroosh Borazjani and A. Roshan (2014), Department of Mechanical and Manufacturing Engineering, Faculty of Engineering, University Putra Malaysia43400 UPM, Serdang, Selangor, Malaysia.

5.Keyan Wang, B. Eng.(2016)," Calibration of the Johnson-Cook failure Parameters as the chip separation criterion in the modeling of the orthogonal metal cutting process", Mechanical Engineering, McMaster University.

6. Evans, K. A. (1993). "Properties and uses of aluminum oxides and aluminum hydroxides"In Downs, A. J. The Chemistry of Aluminium ,Indum and Gallium. Blakie Academic. 
7. Y.-G. Zhang, M.-W. Lu, and K.-c. Hwang, (1994), "Finite element modeling of reinforced concrete structures, " Finite Elem. Anal. Des., vol. 18, no. 1-3, pp. 601-620.

8. Maan. A.T. (2000) "Finite Element Simulation of Chip Formation and Comparison with Machining Experiments", Ph. D Thesis, University of Technology / Baghdad.

9. Erik Oberk, Franklin D. Jones, Holbrook L. Horton, and Henry H. Ryffel ( 2008), "Machinery? s Handbook 28th Edition", Industrial Press Inc., New York, pp.720-757,.

10. Lafta, A.F. "The Cutting Performance of Sailon Ceramic Tool (1983)",Ph. D. Thesis, University of Aston, September, 